\title{
Effect of pre-straining on the aging behavior and mechanical properties of an $\mathrm{Al}-\mathrm{Cu}-\mathrm{Mg}-\mathrm{Ag}$ alloy
}

\author{
M. Gazizov*, R. Kaibyshev \\ Belgorod State University, Pobeda 85, Belgorod 308015, Russia
}

\section{A R T I C L E I N F O}

\section{Article history:}

Received 30 September 2014

Received in revised form

20 November 2014

Accepted 30 November 2014

Available online 9 December 2014

Keywords:

Aluminum alloys

Thermomechanical processing

Ageing

Hardening

Precipitation

Mechanical characterization

\begin{abstract}
A B S T R A C T
The effects of cold deformation prior to aging on the precipitation behavior, microstructure and mechanical properties of an $\mathrm{Al}-5.6 \mathrm{Cu}-0.72 \mathrm{Mg}-0.5 \mathrm{Ag}-0.32 \mathrm{Mn}-0.17 \mathrm{Sc}-0.12 \mathrm{Zr}$ (in wt\%) alloy were investigated. Pre-straining disrupts the formation of $\mathrm{Mg}-\mathrm{Ag}$ co-clusters, modifying the normal precipitation sequence. A strong increase in the dislocation density by a factor of 100 leads to a $\sim 40 \%$ decrease in the number density, $N_{V}$, of the $\Omega$-phase at pre-strains of $\varepsilon \geq 1 \%(\varepsilon \geq 0.01)$. The aspect ratios of the platelets in this phase increased from $\sim 21$ to $\sim 42$ after a negligible pre-strain of $\leq 1 \%(\varepsilon \leq 0.01)$ and further decreased to $\sim 25$ in the pre-strain interval of $1-80 \%(\varepsilon \sim 0.01-1.61)$. In addition, the nucleation of the Cu-rich $\theta^{\prime}$-phase occurs on dislocations. The heterogeneous nucleation of the thick $\Omega$-phase particles with low aspect ratios $(\sim 12)$ and equiaxed particles of S-phase with dimensions $\leq 5 \mathrm{~nm}$ on the deformation-induced boundaries was found. After peak aging, the yield stress (YS) and ultimate tensile strength (UTS) increased from $478 \pm 4 \mathrm{MPa}$ and $522 \pm 8 \mathrm{MPa}$ for the as-quenched alloy to $516 \pm 4 \mathrm{MPa}$ and $568 \pm 6 \mathrm{MPa}$ in the longitudinal and $554 \pm 5 \mathrm{MPa}$ and $601 \pm 3 \mathrm{MPa}$ in the transversal directions, respectively, for the alloy subjected to pre-straining with a rolling reduction of $80 \%(\varepsilon \sim 1.61)$. Cold rolling prior to aging induces the anisotropy in mechanical behavior through the formation of deformation bands.
\end{abstract}

(c) 2014 Elsevier B.V. All rights reserved.

\section{Introduction}

Age-hardenable aluminum alloys belonging to the $\mathrm{Al}-\mathrm{Cu}-\mathrm{Mg}-$ $\mathrm{Ag}$ system are used in the aerospace industry due to their attractive combination of high specific strength, good fracture toughness and enhanced creep resistance attributed to the highly efficient strengthening by the $\Omega$-phase $[1-10]$. This phase is a coherent modification of the equilibrium $\theta$-phase $\left(\mathrm{Al}_{2} \mathrm{Cu}\right)$ that forms as a uniform dispersion of thin, hexagonal plates with large aspect ratios (diameter/thickness) on the $\{111\}_{\alpha}$ habit planes [2-5,11-15]. The replacement of the $\mathrm{Al}$ atoms in the entire first and second layers on the broad faces of the $\Omega$-phase plate in the direction normal to the $\Omega / \mathrm{Al}$ interface with either $\mathrm{Ag}$ or $\mathrm{Mg}$, respectively, lowers the interfacial energy of the $(001)_{\Omega} / /(111)_{\alpha}$ interface and aids in accommodation of the misfit and the volumetric strain that exist between the $\Omega$-phase and the Al lattice [4,5]. Thus, $\mathrm{Ag}$ and $\mathrm{Mg}$ segregation at the interfaces provides a high degree of coherence on the broad faces. The edges of the plates can lose coherency through $\Omega$ plate thickening [4]. The precipitation sequence of $\mathrm{Al}-\mathrm{Cu}-\mathrm{Mg}-\mathrm{Ag}$ can be summarized as

\footnotetext{
* Corresponding author. Tel./fax: +7 4722585456.

E-mail addresses: gazizov@bsu.edu.ru (M. Gazizov), rustam_kaibyshev@bsu.edu.ru (R. Kaibyshev).
}

follows $[4,6,7,11]$ :

SSSS $\rightarrow$ Guinier-Preston(GP)zones $\rightarrow \Omega-$ phase $\rightarrow \theta-$ phase

$+S-$ phase

The role of $\mathrm{Ag}$ is to act as an effective trap for $\mathrm{Mg}$ atoms $[6,8,11,12]$. These aggregates combine with $\mathrm{Cu}$ to form $\{111\}_{\alpha}$ GP zones that continuously evolve into the $\Omega$-phase through direct allotropic transformation [11]. In Stage III, the $\Omega$-phase is replaced by the $\theta$-phase, mainly through the separate nucleation and growth of the $\theta$-phase at a very slow rate under static aging [13] or the in situ allotropic transformation $\Omega$-phase $\rightarrow \theta$-phase under plastic deformation at intermediate temperatures [7]. Most of the $\theta$-phase particles nucleate homogenously or on grain boundaries. In addition, $\mathrm{S}$-phases $\left(\mathrm{Al}_{2} \mathrm{CuMg}\right)$ and a small portion of the $\theta$-phase nucleate at matrix dislocations.

Commercial Al-Cu-Mg-Ag alloys, such as AA2139, offer substantially higher yield stresses (YS) and ultimate tensile strengths (UTS) with high levels of damage tolerance if they are cold-worked after quenching and prior to peak aging $[9,16]$. In other words, these alloys are subjected to a T8 temper $[9,10,14]$. In the T8 process, the cold working resulted in a high density of dislocations and dramatically increased the number density of the $\theta^{\prime}$-phase, which forms rectangular or octagonal plates parallel and semicoherent to the $\{100\}_{\alpha}$ planes on lattice dislocations at the 
expense of the $\Omega$-phase [15-17]. Concurrently, the passage of dislocations through the matrix during deformation prior to aging disrupts the clustering of $\mathrm{Ag}$ and $\mathrm{Mg}$ atoms and also alters the vacancy content $[14,15,18]$. As a result, the precipitation sequence in a pre-deformed structure can be re-written as [15]

SSSS $\rightarrow \Omega-$ phase $+\theta^{\prime}-$ phase $\rightarrow \theta-$ phase $+S-$ phase

In the T8 process, there is a competitive process between bulk precipitation of the $\Omega$-phase on $\{111\}_{\alpha}$ habit planes and precipitation of the $\theta^{\prime}$-phase on dislocations on the $\{100\}_{\alpha}$ planes from the supersaturated solid solution. Cold working before aging refines the mean dimensions of the $\Omega$-phase retaining the aspect ratio of the platelets and provides a uniform dispersion of the $\theta^{\prime}$-phase [15]. It was suggested [10] that the $\Omega$-phase that precipitated on the $\{111\}_{\alpha}$ planes is a more effective strengthener than the $\theta^{\prime}$-phase precipitated on the $\{100\}_{\alpha}$ planes [2]. However, it was recently assumed that precipitate plates lying on $\{111\}_{\alpha}$ planes are relatively ineffective in impeding dislocation glide in the fcc lattice. The dispersion strengthening associated with these plates can be even less than the dispersion strengthening attributed to the $\theta^{\prime}$-phase [19]. In general, the effect of the $\mathrm{T} 8$ process on the precipitation and mechanical properties strongly depends on the alloy and pre-strain [20-23].

The goal of this paper is to consider the effect of predeformation by cold tension and rolling on the precipitation behavior and evolution of mechanical properties in an $\mathrm{Al}-\mathrm{Cu}-$ $\mathrm{Mg}-\mathrm{Ag}$ alloy with high $\mathrm{Cu}$-to-Mg ratio during artificial aging. The relationships between the microstructure and mechanical properties will be established. Based on this study, the strengthening potential for achieving a high strength in experimental AA2139 alloy modified by 0.17 wt\% Sc, 0.12 wt\% Zr, 0.1 wt\% Ge and containing no $\mathrm{V}$ by imposing large strain under the thermomechanical processing (TMP) will be evaluated.

\section{Experimental details}

An experimental version of the AA2139 alloy with a chemical composition of Al-5.6Cu-0.72 Mg-0.5Ag-0.32Mn-0.17Sc-0.12Zr$0.1 \mathrm{Ge}$ (wt\%) was prepared using direct-chill, semi-continuous casting process with high cooling rate $[10,24]$. In this process, ingots were cast by the vertical process in which the molted alloy was poured into a water-cooled mold. Then, ingots were subjected to a two-step homogenization annealing at $360{ }^{\circ} \mathrm{C}$ for $6 \mathrm{~h}$, followed by subsequent heating to $510{ }^{\circ} \mathrm{C}$ and soaking for $24 \mathrm{~h}[24,25]$. After homogenization annealing these ingots were extruded at $\sim 400{ }^{\circ} \mathrm{C}$ with an extrusion ratio of $2.6: 1$ to rods with a diameter of $50 \mathrm{~mm}$. Next, these rods were hot rolled by duo rolling mill along the main axis to plates with a thickness of $\sim 20 \mathrm{~mm}$. The sheets with a 40-mm width, a 70-mm length and different thicknesses $(1.7,1.9,2.1,2.5,3.0,3.8,7.5 \mathrm{~mm})$ were cut from the hot rolled plates using wire electric discharge machine Sodick AQ300L. These plates were pre-heated at $525{ }^{\circ} \mathrm{C}$ for $1 \mathrm{~h}$ followed by water quenching.

These sheets were processed in four different conditions (Fig. 1). First, in the $\mathrm{T} 4$ process, the sheets with a $1.5-\mathrm{mm}$ thickness were naturally aged with no pre-straining. Second, in the T6 process, the sheets with a $1.5-\mathrm{mm}$ thickness were artificially aged with no prestraining (Fig. 1a). Third, in the T65X process the sheets with a $1.5-\mathrm{mm}$ thickness were cold-worked between quenching and artificial aging (Fig. 1b) using the flat "dog bone" tensile samples with a 16-mm gauge length and a $3 \times 1.5-\mathrm{mm}^{2}$ cross-section to simulate stretching. The axis sample matched with the direction of the previous hot rolling. These samples were tensioned at room temperature and initial strain rates of $\sim 2.1 \times 10^{-3} \mathrm{~s}^{-1}$ up to fixed engineering strains ranging from $1 \%$ to $10 \%$ (true pre-strains ranges from $\sim 0.01$ to $\sim 0.1$ ) at room temperature and followed with artificial aging. Fourth, in the T8XX process the sheets with different thicknesses were cold rolled with a rolling speed of $\sim 2 \mathrm{~m} / \mathrm{min}$ and reductions of $\sim 10 \%, 20 \%, 30 \%, 40 \%$, $60 \%$, and $80 \%$ (true pre-strains of $\sim 0.11, \sim 0.22, \sim 0.36, \sim 0.51, \sim 0.92$, and $\sim 1.61$, respectively) up to a final thickness of $\sim 1.5 \mathrm{~mm}$, which was the same for all the samples (Fig. 1b). The direction of hot rolling and cold rolling was also the same. In all material conditions, the final artificial aging was performed at $190{ }^{\circ} \mathrm{C}$ for $0.5-96 \mathrm{~h}$ in the chamber furnace with air circulation.

The hardness measurements were performed on crosssectional surfaces of the samples cut transversely to the rolling direction. A Wilson Wolpert 402 MVD hardness tester with a constant load of $2 \mathrm{~N}$ and loading time of $15 \mathrm{~s}$ was used. At least ten indentations in arbitrarily selected areas for each data point were performed to determine the average value and standard deviation of Vicker's hardness $\left(\mathrm{HV}_{0.2}\right)$ for each condition. The tensile tests were performed using an Instron 5882 testing machine at ambient temperature and an initial strain rate of $2 \times 10^{-3} \mathrm{~s}^{-1}$ on flat specimens with a $16-\mathrm{mm}$ gauge length and a $3 \times 1.5-\mathrm{mm}^{2}$ cross section after aging at $190{ }^{\circ} \mathrm{C}$ for $2 \mathrm{~h}$. These specimens were cut with the tensile axis in the longitudinal (L) and transversal ( $\mathrm{T})$ directions relative to the rolling direction. For each material condition, three or five tensile tests were conducted, and the YS, UTS and elongation-to-failure, $\delta$, were determined by averaging these parameters of three or five tests.

Samples were electropolished in a solution of $30 \%$ nitric acid and $70 \%$ methanol at $-30{ }^{\circ} \mathrm{C}$ using a Tenupol-5 twin-jet polishing unit for transmission electron microscopy (TEM). The thin foils were examined using a FEI TECNAI-G2 TEM with a double-tilt stage and a field emission gun operated at $200 \mathrm{kV}$. TEM observations were carried out in transmission and scanning (STEM) modes. This TEM was equipped with an EDAX energy dispersive X-ray analyzer. The apparent diameter $(D)$ and thickness $(h)$ of the $\Omega$-phase plates were measured from TEM images with the electron beam orientated parallel to the $[011]_{\alpha}$ zone axis of the matrix. In this case, $1 / 2(2 / 4)$ of the hexagonal plates of the $\Omega$-phase can be imaged as rectangles due to orthogonal projection of particle plates to the image plane (Variants 1 and 2, Fig. 2). Approximately 300-400 measurements of the plate dimensions for each condition were performed using at least ten arbitrarily selected typical TEM images for each data point. The foil thickness, $t$, was determined by the convergent beam electron diffraction (CBED) method using Kossel-Möllenstedt fringes in two-beam condition, which is based on the fact that the distance between a weak fringe and a strong bright fringe in an excited $h k l$ CBED disc of high-order Laue zone (HOLZ) is sensitive to foil thickness [26]. The number density per unit volume, $N_{V}$, of the $\Omega$-phase precipitates was defined using the equation at work [27], which was modified taking into account the fact that the $\Omega$ plates precipitate on the $\{111\}_{\alpha}$ planes (Fig. 2): $N_{V}=\frac{N+N\left(\left(t+D_{\text {ave }}\right) / \sqrt{A_{S}}\right)}{A_{S}\left(t+D_{\text {ave }}\right)}$, where $N$ is a number of counted particles on the TEM image (Variants 1 and 2), $A_{S}$ is a respective area on the TEM image, and $t+D_{a v e}$ is the thickness of the foil area from which the size and number density of precipitates were measured. The standard deviations associated with the measurements of the diameters and thicknesses of the $\Omega$ plates (Figs. 13 and 14 and Table 1) were derived from the particle size distributions. The density of lattice dislocations, $\rho_{d}$, was estimated using intercept relationship $\rho_{d}=(1 / t)\left(\left(n_{1} / L_{1}\right)+\right.$ $\left.\left(n_{2} / L_{2}\right)\right)$ [26,28], where $n_{1}$ and $n_{2}$ are the numbers of intercepts on the sets of orthogonal lines of total lengths $L_{1}$ and $L_{2}$ on the normal TEM or STEM images. Average value and standard deviation of lattice dislocation density and number density of precipitates were estimated on ten arbitrarily selected typical TEM images for each data point. The total volume fraction $(f)$ of $\Omega$ plates within the grain/subgrain interiors was calculated as 

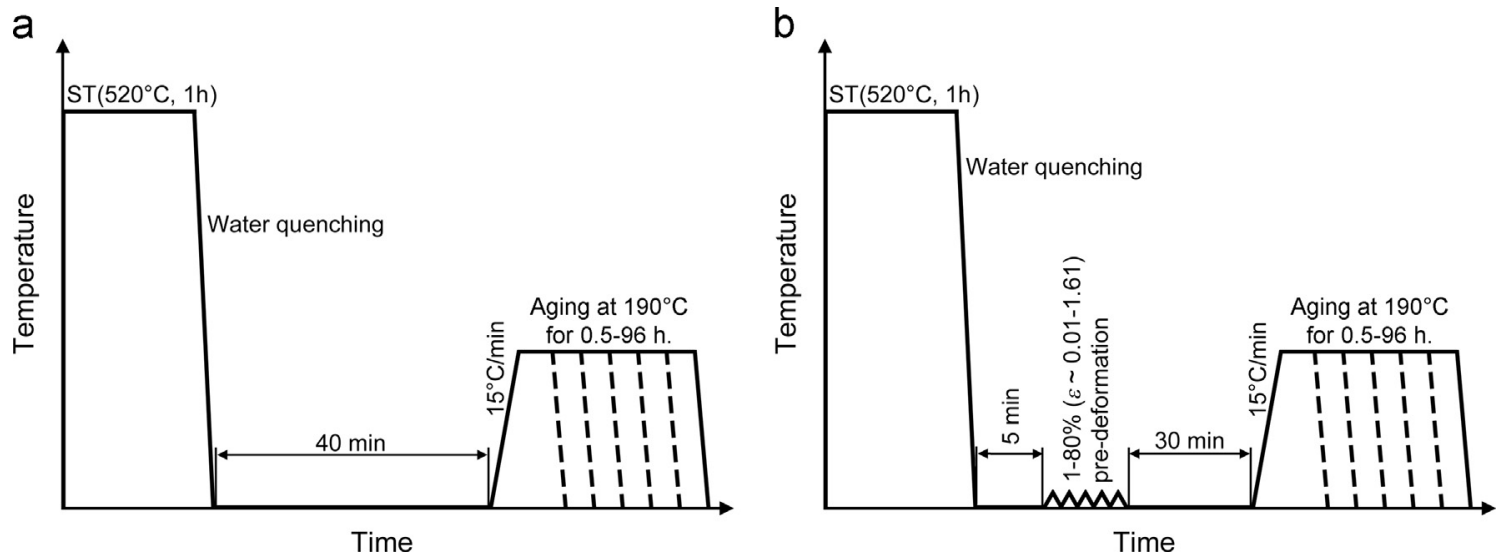

Fig. 1. Scheme of the TMPs (a) in non-deformed (T6 temper) and (b) pre-deformed conditions (T65X and T8XX tempers).

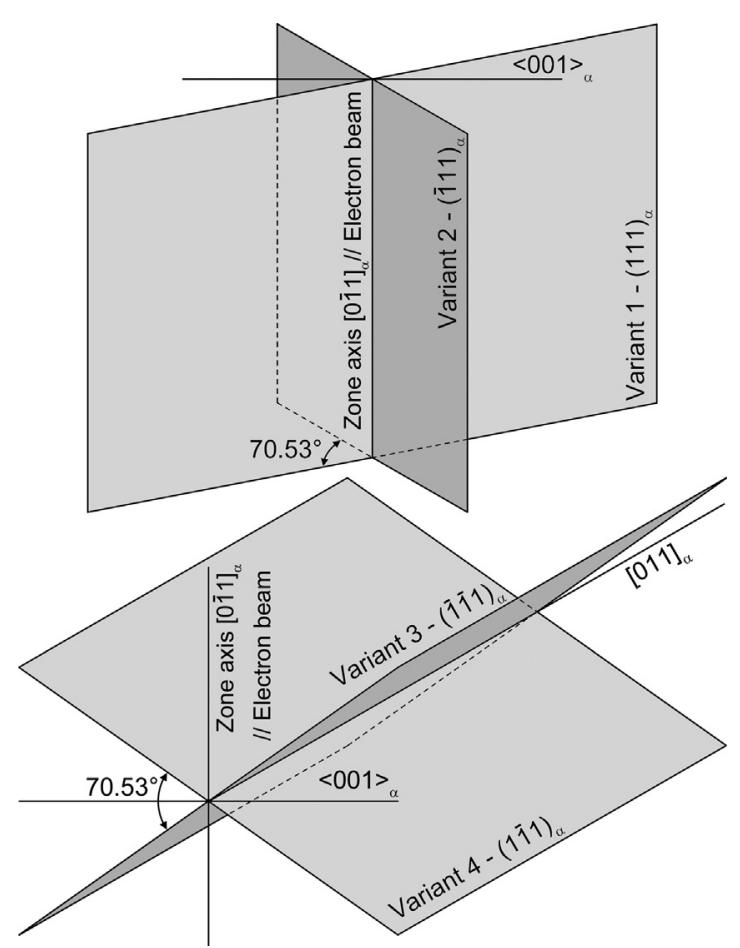

Fig. 2. Schematic diagrams showing spatial orientation of $\Omega$-phase relative to zone axis of $\langle 110\rangle_{\alpha}$ parallel to the electron beam.

\section{Table 1}

Effect of pre-strain followed by aging at $190{ }^{\circ} \mathrm{C}$ for $2 \mathrm{~h}$ on the precipitate statistics of the $\Omega$ plates within the grain/subgrain interiors.

\begin{tabular}{llllll}
\hline $\begin{array}{l}\text { Pre- } \\
\text { deformation }\end{array}$ & $\begin{array}{l}\text { Plate } \\
\text { diameter, } D \\
(\mathrm{~nm})\end{array}$ & $\begin{array}{l}\text { Plate } \\
\text { thickness, } h \\
(\mathrm{~nm})\end{array}$ & $\begin{array}{l}\text { Aspect } \\
\text { ratio }\end{array}$ & $\begin{array}{l}\text { Number } \\
\text { density, } N_{V} \\
\left(\mu \mathrm{m}^{-3}\right)\end{array}$ & $\begin{array}{l}\text { Volume } \\
\text { fraction } f \\
(\%)\end{array}$ \\
\hline $0 \%$ & $20.8 \pm 10.9$ & $0.99 \pm 0.22$ & 21.01 & $9931 \pm 1409$ & 0.33 \\
$1 \%(\varepsilon \sim 0.01)$ & $48.3 \pm 24.6$ & $1.08 \pm 0.35$ & 44.72 & $3615 \pm 1067$ & 0.72 \\
$3 \%(\varepsilon \sim 0.03)$ & $33.4 \pm 16.1$ & $0.78 \pm 0.23$ & 42.82 & $6982 \pm 1668$ & 0.48 \\
$5 \%(\varepsilon \sim 0.05)$ & $31.6 \pm 17.4$ & $0.73 \pm 0.20$ & 43.3 & $6179 \pm 1738$ & 0.35 \\
$7 \%(\varepsilon \sim 0.07)$ & $36.0 \pm 16.4$ & $0.90 \pm 0.24$ & 40.0 & $5421 \pm 1218$ & 0.50 \\
$60 \%$ & $18.7 \pm 9.0$ & $0.87 \pm 0.21$ & 21.5 & $7274 \pm 1819$ & 0.17 \\
$(\varepsilon \sim 0.92)$ & & & & & \\
$80 \%$ & $22.9 \pm 9.5$ & $0.81 \pm 0.18$ & 28.3 & $7488 \pm 1890$ & 0.25 \\
$(\varepsilon \sim 1.61)$ & & & & & \\
\hline
\end{tabular}
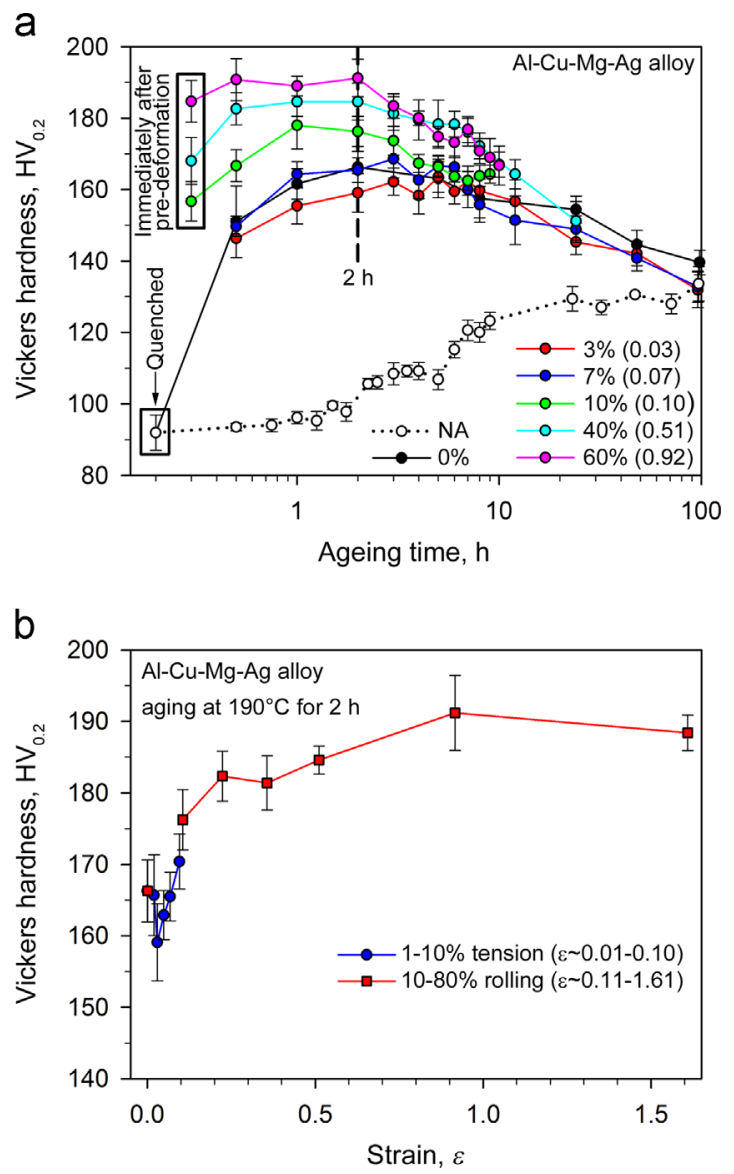

Fig. 3. Effect of (a) time for the alloy in T4 (naturally aged, NA), T6 $(0 \%+$ aging at $\left.190{ }^{\circ} \mathrm{C}\right)$, T65X $\left(3 \%(\varepsilon \sim 0.03)\right.$ and $7 \%(\varepsilon \sim 0.07)+$ aging at $\left.190{ }^{\circ} \mathrm{C}\right)$ and T8XX $(10 \%$ $(\varepsilon \sim 0.11), 40 \%(\varepsilon \sim 0.51), 60 \%(\varepsilon \sim 0.92)+$ aging at $\left.190{ }^{\circ} \mathrm{C}\right)$ conditions and (b) strain through tension with strains from 1 to $10 \%(\varepsilon \sim 0.01-0.10)$ and rolling with reductions from $10 \%$ to $80 \%(\varepsilon \sim 0.11-1.61)$ on hardness.

$f=\pi\left(D_{\text {ave }}^{2} / 4\right) h_{\text {ave }} N_{V}$, where $h_{\text {ave }}$ is the average thickness of the $\Omega$ plates.

\section{Results}

\subsection{Hardness}

Fig. 3 depicts the Vicker's hardness as a function of time for $96 \mathrm{~h}$ in the T4, T6, T65X and T8XX conditions. The hardness of the 
as-quenched specimen was approximately $92 \mathrm{HV}_{0.2}$. During natural aging, the hardness starts to increase after $2 \mathrm{~h}$ to a maximum of $\sim 125 \mathrm{HV}_{0.2}$ at $20 \mathrm{~h}$ (Fig. 3). Therefore, no rapid hardening, which is an important feature of $\mathrm{Al}-\mathrm{Cu}-\mathrm{Mg}$ alloys [15], occurs. During artificial aging, the hardness of the non-deformed specimen increased gradually to a peak of $\sim 166 \mathrm{HV}_{0.2}$ at $2 \mathrm{~h}$. For specimens tensioned at $3 \%(\varepsilon \sim 0.03)$, the hardness peak shifts for $6 \mathrm{~h}$ (Fig. 3a). Further increases in the pre-strain shift the hardness peak to short time aging. However, the peak hardness of $\sim 168 \mathrm{HV}_{0.2}$ is independent of the pre-straining for the $\mathrm{T} 65 \mathrm{X}$ condition (Fig. 3a). This result is in contrast with the previous work [15] in which pre-straining via rolling with a reduction of $6 \%$ leads to decreased peak hardness and shifts to longer time under artificial aging at 160 and $200{ }^{\circ} \mathrm{C}$.

Cold rolling is more effective for strengthening alloys than tension (Fig. 3b). The hardness of the alloy subjected to cold rolling with $10 \%(\varepsilon \sim 0.11)$ is slightly higher than the alloy tensioned with $10 \%$ ( $\varepsilon \sim 0.10$ ). The average hardness of the as-quenched and coldrolled samples were consistently increased to $\sim 157, \sim 168$ and $\sim 185 \mathrm{HV}_{0.2}$ after true strains of $\sim 0.11, \sim 0.51$ and $\sim 0.92$, respectively. The pre-straining before peak aging results in an acceleration of the overall precipitation kinetics and increasing peak hardness with increasing strain [20]. The peaks of $\sim 175, \sim 182$ and $\sim 192 \mathrm{HV}_{0.2}$ were achieved after $1-2 \mathrm{~h}$ of aging. In the overaging stage, the hardnesses of the cold rolled specimens decrease faster than in the T6 or T65X conditions. After $20 \mathrm{~h}$ of aging, the hardness is independent of pre-strain (Fig. 3a).

\subsection{Mechanical properties}

The typical engineering stress-strain curves of the alloy and the effect of time on YS, UTS and total elongation-to-failure $(\delta)$ are presented in Figs. 4 and 5, respectively. The shape of the $\sigma-\varepsilon$ curves is similar for all material conditions (Fig. 4). The $\sigma-\varepsilon$ curves are typical for peak-aged aluminum alloys with a high $(\geq 0.9) \sigma_{0.2} /$ $\sigma_{B}$ ratio, which tends to increase from 0.9 in the T6 condition to $\sim 0.95$ in the T880 condition. Limited strain hardening takes place after yielding, and an apparent steady state is attained after a small strain (Fig. 4). A significant uniform elongation is provided. In the $\mathrm{T} 65 \mathrm{X}$ condition, the increasing pre-strain leads to decreased strength and increased ductility (Fig. 5), which is attributed to a shift in the peak strength to $\geq 3 \mathrm{~h}$ (Fig. 3a). At $\varepsilon \sim 0.10(10 \%$ tension) and $\varepsilon \sim 0.11$ (10\% rolling), the YS, UTS and $\delta$ values in the L

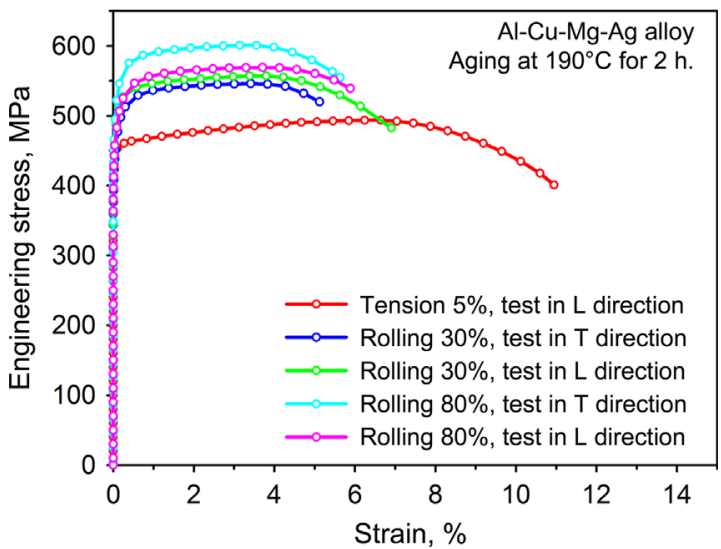

Fig. 4. Typical engineering stress-strain $(\sigma-\varepsilon)$ curves for the alloy in the asquenched condition and then subjected to tension with $5 \%(\varepsilon \sim 0.05)$ and rolling with a reduction of $30 \%(\varepsilon \sim 0.36)$ and $80 \%(\varepsilon \sim 1.61)$ followed by aging at $190{ }^{\circ} \mathrm{C}$ for $2 \mathrm{~h}$ in the $\mathrm{T}$ and $\mathrm{L}$ directions. direction are the same (Fig. 5a and b). After $40 \%$ ( $\varepsilon \sim 0.51$ ), the YS increase is $+18 \%$ and the UTS increase is $+13 \%$ in comparison with the T6 condition, but a decrease in the elongation-tofailure takes place. An insignificant anisotropy of the mechanical properties is observed in this strain interval. The YS and UTS values in the L direction are greater by 10-20 MPa than those of the samples tested in the T direction. Therefore, the material in the T810-840 conditions exhibits essentially isotropic strength characteristics. In contrast, there is about a two-fold anisotropy in ductility after rolling with reduction of $10 \%(\varepsilon \sim 0.11)$. This anisotropy diminishes with increasing rolling reduction.

The main feature of the mechanical behavior of the material rolled with $40 \%(\varepsilon \sim 0.51)$ is increasing YS and UTS values in T direction with increasing pre-strain, while these values in the $\mathrm{L}$ direction remain nearly unchanged. After $80 \%(\varepsilon \sim 1.61)$, the YS and UTS in the transverse direction are higher by $\sim 50 \mathrm{MPa}$ than those of the samples tested in the L direction. The alloy in the T880 condition exhibits minor anisotropy in its mechanical behavior. No anisotropy in ductility was found after extensive rolling.

\subsection{Deformation microstructure}

The microstructure of the alloy in as-quenched condition has been described in detail in previous works [7,24,25]. Boundary particles of the primary $\theta$-phase and ternary $\mathrm{W}$-phase play no role in dispersion hardening. Nanoscale particles of $\beta^{\prime}$-phase $\left(\mathrm{Al}_{3} \mathrm{Sc}\right)$ with coherent interfaces were located within the aluminum matrix and may effectively pin mobile dislocations [29]. However, their distribution is non-uniform, and their volume fraction is low [24]. As a result, this dispersion may affect the formation of dislocation structures only locally within separate initial grains [25]. The dislocation density in the as-quenched condition was low $\left(\rho_{d} \sim 2 \times 10^{12} \mathrm{~m}^{-2}\right)$.

Tension greatly increases the density of the lattice dislocations by a factor of 100 or even higher (Figs. 6 and 7). At a strain of 7\% ( $\varepsilon \sim 0.07$ ), tangled dislocations are observed, and the dislocation density reaches $\rho_{d} \sim 1.8 \times 10^{14} \mathrm{~m}^{-2}$ (Fig. 6a). Tension and cold rolling produce nearly the same dislocation density in the strain interval of $7-60 \%(\varepsilon \sim 0.07-0.92)$ (Fig. 7). The main difference between these two deformation techniques consists of deformation banding, which was found only in the cold rolled samples. After rolling to $10 \%(\varepsilon \sim 0.11)$, the poorly defined deformation bands could be distinguished (Fig. 6b). It is apparent that the deformation band thickness is affected by the interparticle spacing of the $\mathrm{W}$-phase (Fig. 6c). The deformation structure remained nearly unchanged (Fig. 7) upon further deformation up to $40 \%$ ( $\varepsilon \sim 0.51$ ). The formation of well-defined deformation bands takes place at $60 \%(\varepsilon \sim 0.92)$ (Fig. 6 d). At $80 \%(\varepsilon \sim 1.61)$, two or more families of deformation bands and shear bands delimited by dislocation-free boundaries evolved (inset in Fig. 6e). The initial grains are subdivided into separate crystallites bounded by dislocation boundaries. The dislocation density within these crystallites reaches a very high value of $\sim 2 \times 10^{15} \mathrm{~m}^{-2}$.

\subsection{Precipitation behavior during pre-straining}

The samples were held from 12 to $24 \mathrm{~h}$ after pre-straining before microstructural characterization. Huang et al. [23] recently showed that pre-straining effectively suppresses the formation of the GP zones and other transition phases during natural aging in $\mathrm{Al}-\mathrm{Cu}$ alloys, but the regular precipitation sequence may be bypassed with the assistance of strain-induced defects. To evaluate the effect of pre-straining on the distribution of secondary phases, microstructural analysis of samples tensioned with $7 \%(\varepsilon \sim 0.07)$ and cold rolled with $80 \%$ ( $\varepsilon \sim 1.61$ ) was performed (Figs. 8a and 9a, respectively). 

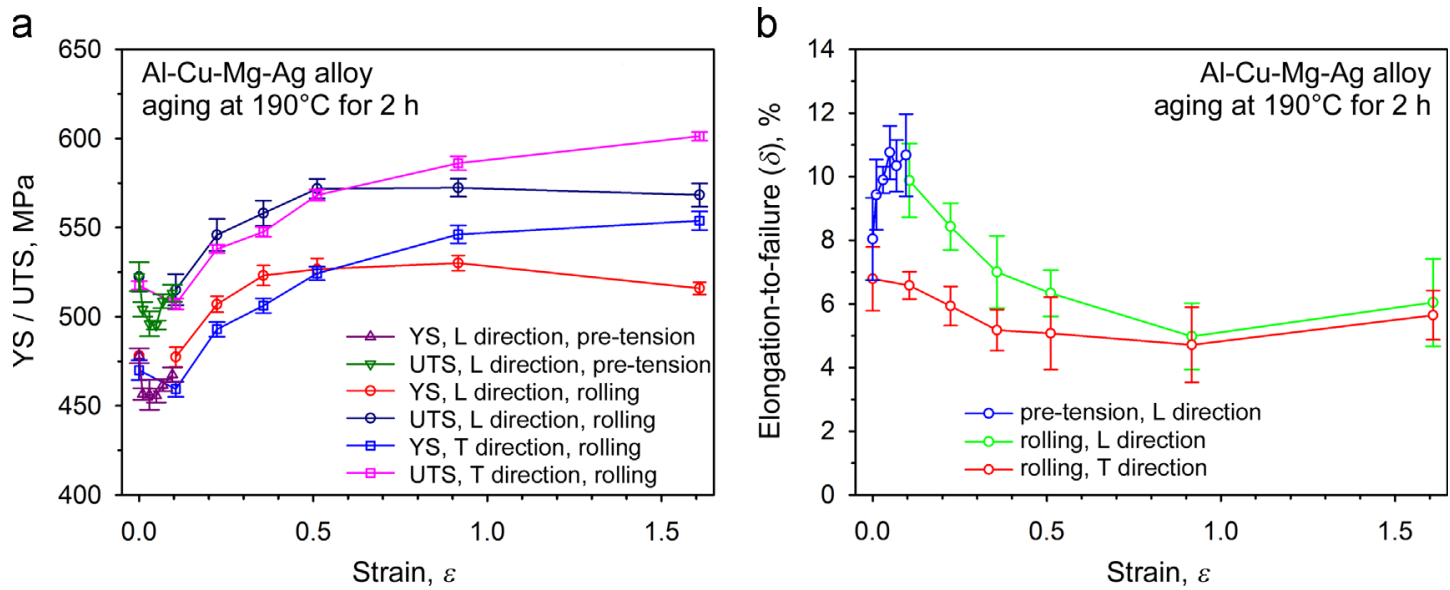

Fig. 5. YS, UTS (a) and elongation-to-failure and (b) as functions of pre-strain followed by aging at $190{ }^{\circ} \mathrm{C}$ for $2 \mathrm{~h}$ in $\mathrm{L}$ and $\mathrm{T}$ directions to the deformation axis.

The corresponding SAED patterns do not exhibit continuous diffuse streaks (Fig. 8b) parallel to the $\langle 100\rangle_{\alpha}$ directions through the $\{200\}_{\alpha}$ spots in the Cu-rich GP zones $[11,12]$. The faint streaks with maximum intensities near the $1 / 2\{200\}_{\alpha}$ positions (arrows in the SAED shown in Fig. 8b) can result from $\mathrm{Cu}+\mathrm{Mg}$-rich GPB (Guinier-Preston-Bagaryatsky) zones precipitated in $\mathrm{Al}-\mathrm{Cu}-\mathrm{Mg}$ alloys during early stages of natural aging [11,12,30-34]. However, no unambiguous evidence for the formation of the GPB zones was obtained under tension followed by natural aging. The detailed analysis of the SAED patterns for the alloy after tension and cold rolling (Figs. 8c and 9b, respectively) does not show any streaks parallel to the $\langle 111\rangle_{\alpha}$ directions caused by the shape effects of plate-like precipitates in the $\{111\}_{\alpha}$ planes from $\mathrm{Mg}-\mathrm{Ag}$ co-clusters [8]. Therefore, pre-straining ceases the formation of GP zones or $\mathrm{Mg}-\mathrm{Ag}$ co-clusters under subsequent natural aging.

Two types of precipitations after pre-straining under tension were revealed (Fig. 8). The TEM images did not allow for distinguishing the fine precipitates in the cold deformed condition because of the crystallographic contrast due to the high dislocation density. However, the first type of secondary phases was classified by analyzing the SAED patterns taken on $\langle 100\rangle_{\alpha}$. In Fig. 8a (inset), these particles have distinct $\{021\}_{\alpha}$ habit planes, which correspond to the lath-shaped S-phase (Type I or S1) observed predominantly in $\mathrm{Al}-\mathrm{Cu}-\mathrm{Mg}$ alloys after artificial aging [12,31-33]. Particles of this phase have a thickness of $5 \mathrm{~nm}$ or less and exhibit specific contrast indicating a coherent strain. Therefore, these particles are in fact the $S^{\prime}$-phase, which is the coherent/semicoherent form of the S-phase nucleated on dislocation loops [12,31-34]. The diffraction spots respective to the orientation relationships (ORs) and crystal structure of the S-phase could not be distinguished on the SAED pattern because the volume fraction of this phase was very small. The diffraction spots at the $1 /$ $2\{220\}_{\alpha}$ positions (circled in SAED of Fig. 8b) were identified as originating from the $\theta^{\prime}$-phase $[11,12]$. Thus, there is evidence of the formation of transient $S^{\prime}$-phase and $\theta^{\prime}$-phase under tension followed by natural aging. It is apparent that pre-straining promotes nucleation of these phases on dislocations. The same phases were identified after extensive rolling.

\subsection{Precipitation behavior during aging}

Taking into account the aforementioned data, we may presume that in the peak aged specimens the distributions of secondary phases described below have little sense to natural aging, which occurs in the as-quenched alloy (Fig. 3a), and result from artificial aging, mainly. Bright-field TEM images of the alloys after prestraining with $7 \%(\varepsilon \sim 0.07)$ followed by under-aging at $190{ }^{\circ} \mathrm{C}$ for $0.5 \mathrm{~h}$ are shown in Fig. 10. Two types of particles in the forms of platelets with $\{111\}_{\alpha}$ habit planes and needle shapes with the main axis along $\langle 001\rangle_{\alpha}$ were identified as the $\Omega$-phase and the $\mathrm{S}^{\prime \prime}$-phase (GPB2 [31-35]), respectively. It is worth noting that $\mathrm{GPB} / \mathrm{S}^{\prime \prime}$-phase precipitates after long-term artificial aging in $\mathrm{Al}-\mathrm{Cu}-\mathrm{Mg}$ alloys $[12,31,33]$ and its precipitation after $0.5 \mathrm{~h}$ even at $190{ }^{\circ} \mathrm{C}$ is quite unusual. The morphologies of these particles were confirmed by the projections taken on the $\langle 110\rangle_{\alpha}$ and $\langle 100\rangle_{\alpha}$ zone axes in Fig. 10a and b, respectively. The weak diffraction streaks caused by the rod-shape of the $\mathrm{S}^{\prime \prime}$-phase (GPB2) [12,32] and located parallel to the $\langle 001\rangle_{\alpha}$ direction are arrowed in the SAED pattern in Fig. 10a. The preferred orientation of the $\Omega$-phase plates was confirmed in the SAED pattern, where different streak intensities were found in the $\langle 111\rangle_{\alpha}$ and $\langle 11 \overline{1}\rangle_{\alpha}$ directions (Fig. 10a).

Bright-field TEM images of alloys pre-strained using tension and rolling followed by peak aging at $190{ }^{\circ} \mathrm{C}$ for $2 \mathrm{~h}$ are shown in Figs. 11 and 12, respectively. In all conditions, the electron beam was parallel to the $\langle 110\rangle_{\alpha}$ direction. The effect of the pre-strain on the characteristics of the $\Omega$-phase after the aging is summarized in Table 1 and Fig. 13. In general, two types of secondary phases were observed. In addition, there are differences in the morphologies between the particles belonging to each type. The first type of secondary phase is the $\Omega$ platelets; their volume fraction is high. The particles of this phase are uniformly distributed within the aluminum matrix at pre-strains of $\leq 40 \%(\varepsilon \leq 0.51)$ (Fig. 11). No evidence for a dominant orientation of the $\Omega$ plates along the $\{111\}_{\alpha}$ plane was found in the SAED patterns. The pre-straining affects the dimensions and number density of the $\Omega$-phase particles (Figs. 12 and 13, Table 1). The pre-straining of $1 \%$ ( $\varepsilon \sim 0.01$ ) leads to a $+180 \%$ increase in the average diameter of the $\Omega$-phase, while the plate thickness remains unchanged. The aspect ratio increases from $\sim 21$ to $\sim 45$. At the same time, the number density, $N_{V}$, decreases by a factor of $\sim 2.7$. Further increases in the tension strain lead to decreasing dimensions of the $\Omega$-phase, but the aspect ratio retains the high level of $\sim 40$ (Table 1$)$. The $N_{V}$ value increases and, at $3 \%(\varepsilon \geq 0.03)$, is about two-fold greater than the number density of the alloy pre-strained at $1 \%(\varepsilon \sim 0.01)$ (Table 1$)$. At $>40 \%(\varepsilon>0.51)$, the aspect ratio decreases to $\sim 25$ due to a decrease in the plate diameter (Table 1 , Fig. 12). Thickness of the $\Omega$-phase ranges from 0.75 to $1 \mathrm{~nm}$.

Two types of the $\Omega$-phase were observed after rolling with reductions of $\geq 10 \%$ ( $\varepsilon \geq 0.11$ ) (Fig. 12a and b). The first type was described above. The second type is thick $\Omega$ plates with thicknesses of $2.2-2.5 \mathrm{~nm}$ and low aspect ratios of $\sim 12$ (Fig. 14). At 

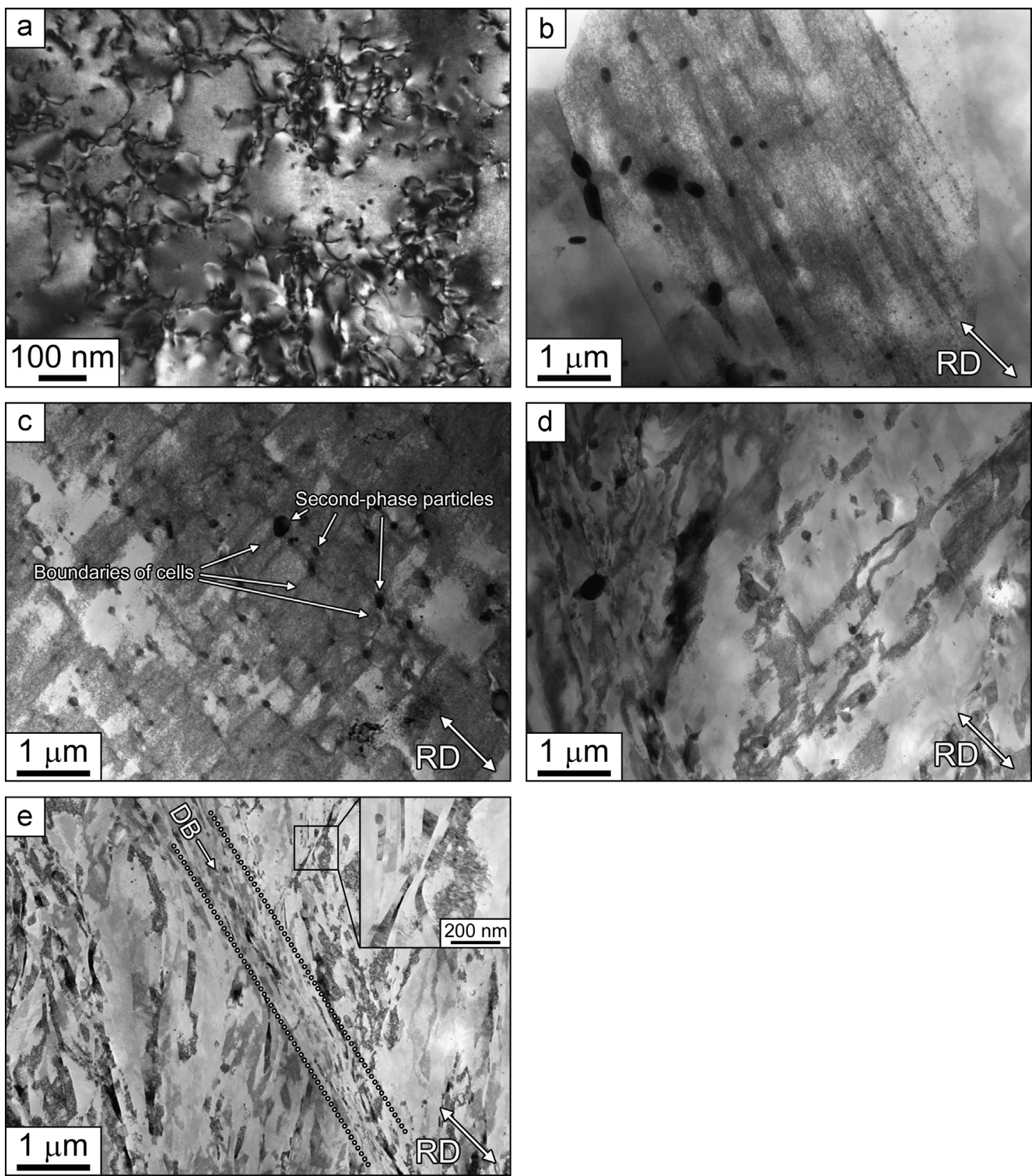

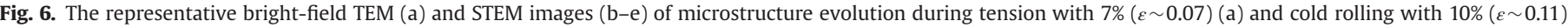
(b), $40 \%(\varepsilon \sim 0.51)$ (c), 60\% ( $\varepsilon \sim 0.92)$ (d) and $80 \%$ ( $\varepsilon \sim 1.61)$ (e). RD - rolling direction and DB - deformation band.

$\geq 60 \%$ ( $\varepsilon \geq 0.92$ ), these thick plates are enriched by $\mathrm{Mg}$ and $\mathrm{Ag}$ atoms in addition to $\mathrm{Cu}$ atoms (Fig. 15) and form chains at the boundaries of the deformation bands or shear bands (Figs. 6e and $12 \mathrm{a})$. There is a difference between two types of the $\Omega$-phase. The thick plates have predominant orientations along the orientation of the deformation-induced boundaries, which is close to the $\{111\}_{\alpha}$ plane. The angle between the normal of the boundary plane and the normal of the $\Omega$-phase platelets ranges from 0 to $45^{\circ}$ to fit the orientation of this phase to a $\{111\}_{\alpha}$ habit plane. Only one broad interface of a thick $\Omega$-phase retains fully coherent configuration and specific OR $[1,3-5,8,12,14]$, while the opposite broad interface has a fully or partially semi-coherent structure, and OR at this interface deviate from the $(001)_{\Omega} / /(111)_{\alpha}$ on the value of misorientation $\left(\geq 4^{\circ}\right)$ of a deformation-induced boundary
(Fig. 16). This deviation is attributed to the high density of the thickening ledge $[4,8,17,25]$ on the semi-coherent board interfaces. Therefore, the deformation banding leads to the appearance of relatively coarse platelets of the $\Omega$-phase along the $\{111\}_{\alpha}$ plane with a semi-coherent interface due to heterogeneous nucleation and accelerated growth at dislocation boundaries or boundaries of shear bands. The second type of the $\Omega$-phase could not exhibit unique characteristics, which are inherent to this phase $[4,5,12-15,34]$.

The second type of precipitations is the $\theta^{\prime}$-phase and $\mathrm{S}^{\prime}$-phase (Figs. 11, 12 and 17). Their volume fraction is low. The $\theta^{\prime}$-phase particles have $\{001\}_{\alpha}$ habit plane and are nucleated at dislocations. The precise diffraction streaks originating from this phase and located parallel to the $\langle 001\rangle_{\alpha}$ direction are arrowed in the SAED 
pattern taken along $\langle 110\rangle_{\alpha}$ zone axis in Fig. 11. These streaks are attributed to the plate-like shape of the $\theta^{\prime}$-phase aligned along the $\langle 100\rangle_{\alpha}$ plane. The $\theta^{\prime}$-plates exhibit strong coherency-strain fields. The $S^{\prime}$-phase particles exhibit an essentially round shape with an average size of $\sim 5 \mathrm{~nm}$ (Fig. 17). This disperoid locates at grain boundary and has a semi-coherent interface with Grain $\mathrm{K}$ and incoherent interface with Grain M (Fig. 17). The S'-phase demonstrates a well-defined orthorhombic structure (space group $\mathrm{Cmcm}$, lattice parameters: $a=0.405 \mathrm{~nm}, b=0.927 \mathrm{~nm}, c=0.718 \mathrm{~nm})$ and $\sim 10^{\circ}$ deviation from the specific ORs with Grain $\mathrm{K}\left([100]_{S} / /[100]_{\alpha}\right.$, $[010]_{S} / /[021]_{\alpha},[001]_{S} / /[012]_{\alpha}$ ) (Fig. 17) that is typical for Type I (or S1) S phase [31,34]. No evidence was found for the appearance of Type II S-phase (S2) or S"-phase [12,31,34].

\section{Discussion}

\subsection{Effect of pre-straining on the precipitation sequence}

The plastic deformation applied before aging introduces a large dislocation density even after a small pre-strain, which modifies the precipitation sequence (1). The experimental data suggest that the precipitation sequence (2) for the pre-strained $\mathrm{Al}-\mathrm{Cu}-\mathrm{Mg}-\mathrm{Ag}$ alloys developed in early works was oversimplified. It is apparent that the precipitation of the $\Omega$-phase and the S-phase occur independently through a sequence of metastable phases, and therefore, they should be considered separately. In addition,

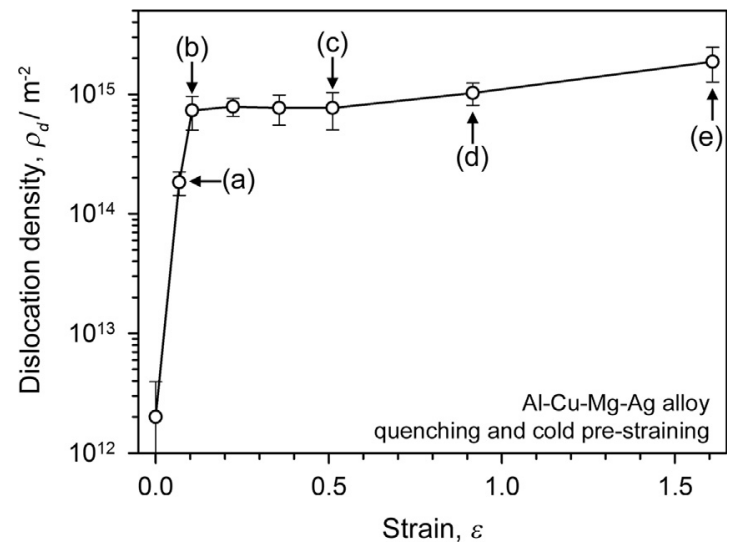

Fig. 7. Evolution of the dislocation density $\left(\rho_{d}\right)$ within the crystallites after the tension and cold rolling. The alphabetical designations correspond to the microstructure in Fig. 5 . precipitation sequences within aluminum matrix and on deformation-induced defects are distinctly different.

The precipitation sequence of the $\mathrm{Al}-\mathrm{Cu}-\mathrm{Mg}-\mathrm{Ag}$ alloy subjected to $1-80 \%(\varepsilon \sim 0.01-1.61)$ pre-strain can be written within grain interiors as follows:

SSSS $\rightarrow$ GPB2 $/ \mathrm{S}^{\prime \prime}-$ phase $\rightarrow \Omega-$ phase

and on dislocations and deformation-induced boundaries as follows:

SSSS $\rightarrow \theta^{\prime}-$ phase + S1 - phase $\rightarrow \Omega-$ phase $+\theta^{\prime}-$ phase

$+\mathrm{S} 1$ - phase

The plastic deformation disrupts co-clusters of $\mathrm{Ag}-\mathrm{Mg}$ aggregating with $\mathrm{Cu}$ atoms, which stops the formation of GP zones within grain interiors. It is apparent that $\mathrm{Ag}$ solutes revert into the solid solution. In the present work no distinct evidence was obtained for the formation of $\mathrm{Cu}-\mathrm{Mg}$ co-clusters, which has structure and orientation similar to ones for the $\Omega$-phase, due to lack of specific diffraction spots or steaks in selected area diffraction or phase contrast $[6,8,11,12,14,32,35]$. However, there are two indirect evidences for the occurrence of this clustering. First, welldefined Stage I of hardening takes place under natural aging but after relatively long holding (Fig. 3) [12,34]. It seems that Ag solute hinders the formation of these clusters. Second, the formation of GPB2/ $/ \mathrm{S}^{\prime \prime}$-phase takes place, and $\mathrm{Cu}-\mathrm{Mg}$ co-clusters play a role of precursor for this phase $[12,33,34]$. There is yet no direct evidence that $\mathrm{Cu}-\mathrm{Mg}$ co-clusters act as precursors for the $\Omega$-phase without the presence of $\mathrm{Ag}$ [14]. However, the $\Omega$-phase may precipitate in $\mathrm{Ag}$-free $\mathrm{Al}-\mathrm{Cu}-\mathrm{Mg}$ alloys subjected to cold working and subsequent artificial aging $[6,14,30]$. It is apparent that very thin plates of the $\Omega$-phase precipitate independently from the supersaturated solid solution subjected to cold working. That is why the prestraining of $1 \%$ by tension results in drastic changes in the dispersion of the $\Omega$-phase. The formation of high dense precipitation of the $\Omega$-phase leads to dissolution of $\mathrm{GPB} 2 / \mathrm{S}^{\prime \prime}$-phase in accordance with Gibbs-Thomson schema [17].

Gliding dislocations sweep the $\mathrm{Cu}$ atoms, which leads to the formation of the $\theta$-phase at these dislocations during natural or artificial aging following the pre-straining. In addition, dislocations comprising boundaries sweep the $\mathrm{Mg}$ and $\mathrm{Ag}$ atoms. It leads to the formation of Type I S-phase [34] and the $\Omega$-phase at these boundaries during artificial aging following extensive rolling. The morphology of these phases is unique. A part of the broad interfaces of these phases is a semi-coherent structure. This may lead to a high coarsening rate of boundary particles of the $\Omega$-phase due to the intensive migration of existing ledges along a flat interface [4]. This coarsening process finally leads to the in situ allotropic transformation of the $\Omega$-phase to the thermodynamically stable $\theta$-phase with incoherent interfaces. It was
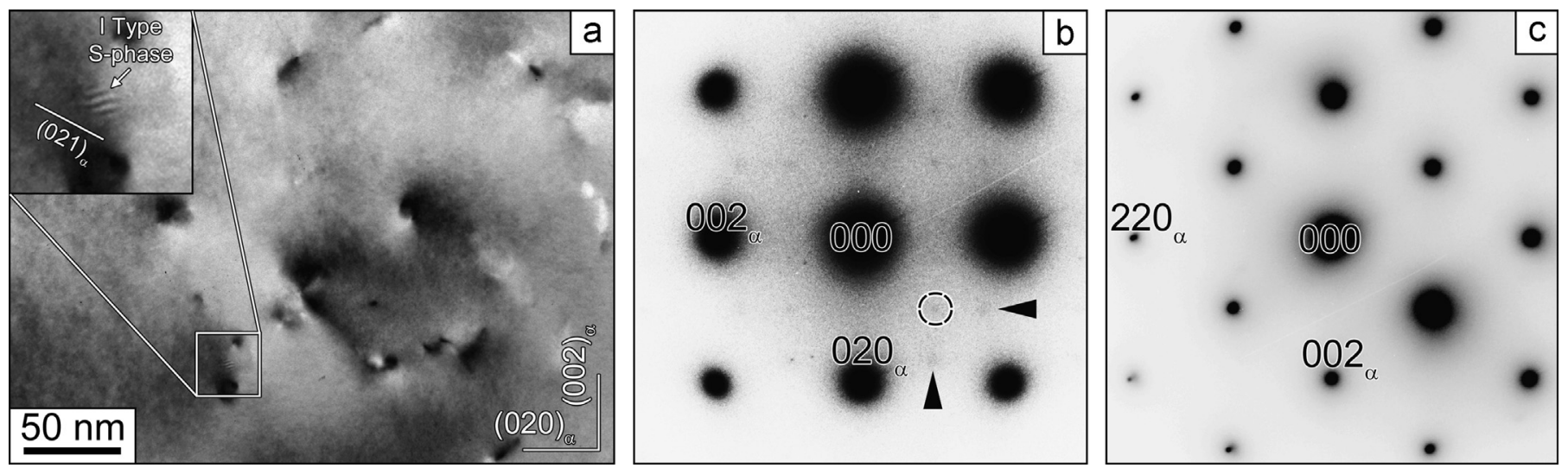

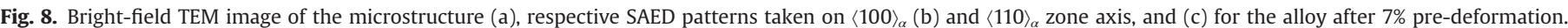
The SAED pattern image was inversed and corrected for the contrast view of the diffraction spots. 

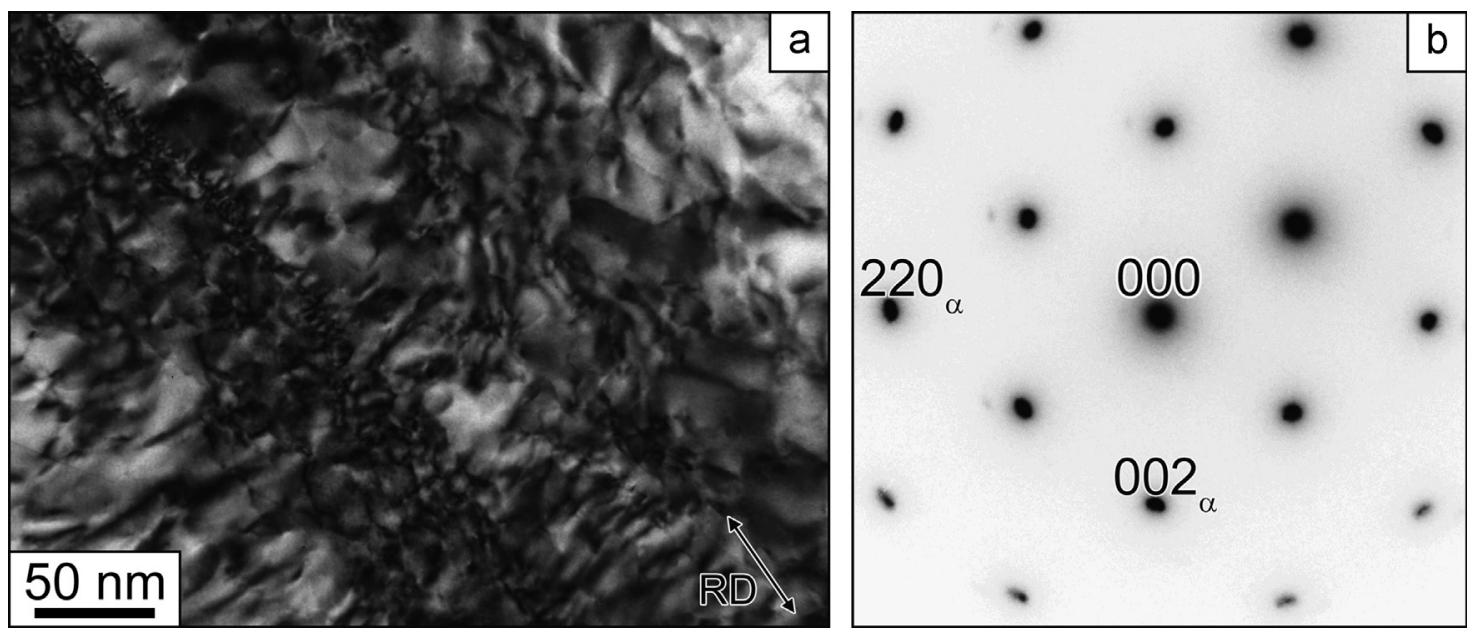

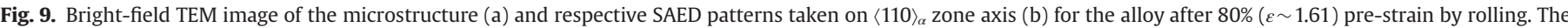
SAED pattern image was inversed and corrected for the contrast between the diffraction spots. RD - rolling direction.
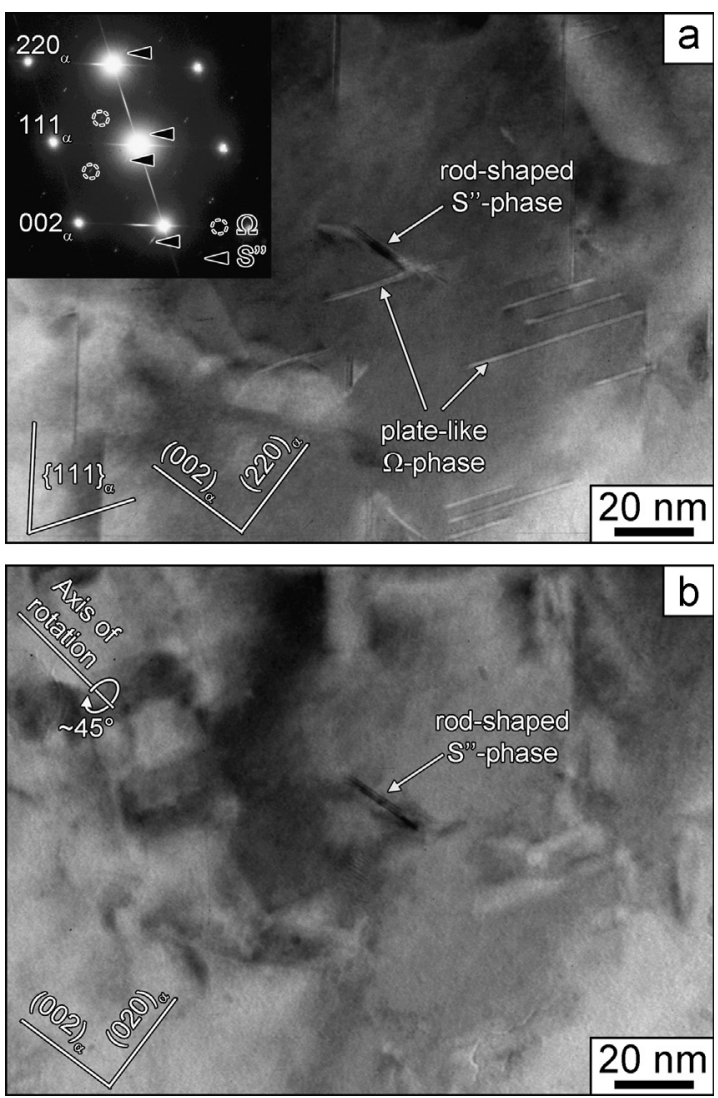

Fig. 10. Bright-field TEM images of the microstructure after $7 \%(\varepsilon \sim 0.07)$ pre-strain using tension and aging at $190{ }^{\circ} \mathrm{C}$ for $0.5 \mathrm{~h}$. For direct comparison, the images are taken in similar areas on the $\langle 110\rangle_{\alpha}$ (a) and $\langle 100\rangle_{\alpha}$ zone axes (b). The SAED pattern image was corrected for the contrast between the diffraction spots.

not evident in the present work. However, a similar process of phase transformation of the $\Omega$-phase was observed under plastic deformation at $250-300{ }^{\circ} \mathrm{C}[7,25]$.

\subsection{Effect of pre-straining on the mechanical properties}

The high strength of the $\mathrm{Al}-\mathrm{Cu}-\mathrm{Mg}-\mathrm{Ag}$ alloy in the peak-aged condition is attributed to the superposition of different strengthening mechanisms. In the as-quenched material, the dispersion of the $\Omega$-phase platelets is the main contributor to the overall strength. The role of the S-phase is minor due to its low volume fraction. Pre-straining followed by peak aging changes the hardening mechanisms. Three pre-strain intervals could be distinguished by the effect of the deformation structure on the precipitation behavior and mechanical properties. At very small strains $\leq 1 \%(\varepsilon \leq 0.01)$, an increase in the dislocation density is compensated by the decreasing number density, $N_{V}$, of the $\Omega$-phase. It is known $[2,3,10]$ that the increase in the strength produced by the $\{111\}_{\alpha}$ plates of this phase is superior, and increasing the aspect ratio of the platelets of this phase increases the strength originating from these very shear-resistant precipitates. Decreasing the $N_{V}$ value of the $\Omega$-phase plates lying on the $\{111\}_{\alpha}$ planes strongly reduces their strengthening ability [19]. The probability of an encounter between a dislocation gliding on a $\{111\}_{\alpha}$ plane and the $\Omega$-phase plates significantly decreases, which leads to an increased mean free path of the mobile dislocations, decreasing the strengthening effect originating from the $\Omega$-phase despite its increased volume fraction.

In the strain interval of $3-10 \%(\varepsilon \sim 0.03-0.51)$, the precipitates have an approximately constant aspect ratio of $\sim 40-45$ and

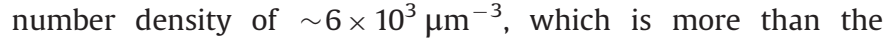
optimum strengthening value for $N_{V}$ [19] by a factor of $\sim 6$. As a result, the contribution of the $\Omega$-phase plates to the dispersion strengthening is independent on the pre-strain. The increasing YS in this interval of pre-strains is attributed to the increasing dislocation density with pre-strain and nucleation of $\theta^{\prime}$-phase and $S^{\prime}$-phase at these dislocations. At pre-strains $\geq 10 \%(\varepsilon \geq 0.11)$, the contribution of the $\Omega$-phase plates to the overall strength decreases due to the nucleation of this phase at dislocation boundaries, which decreases the aspect ratios of these plates within grain interiors. This decrease is compensated by an increasing contribution of the deformation strengthening due to increase of dislocation density with pre-strain. In addition, the grain size strengthening attributed to the formation of well-defined deformation bands starts to play an important role in the overall strengthening [36]. It is worth noting that the formation of deformation bands in the preferential direction is responsible for the appearance of strength anisotropy [37,38]. The preferred orientation of the thick plates of the $\Omega$-phase along these boundaries may also contribute to this anisotropy. The combination of these three strengthening mechanisms provides excellent YS and 

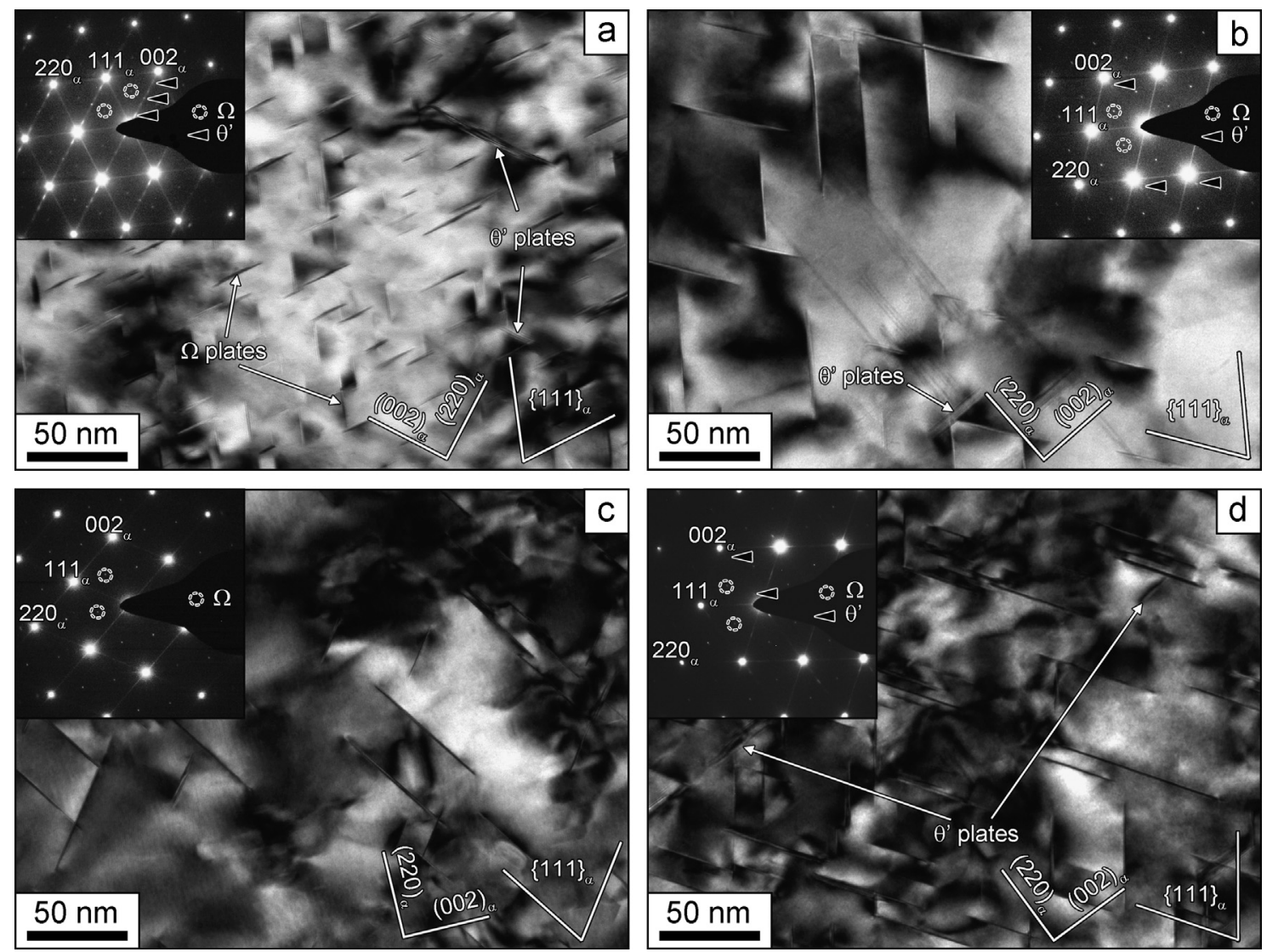

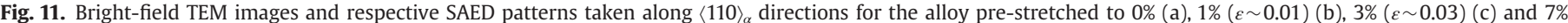
$(\varepsilon \sim 0.07)(\mathrm{d})$ and aged at $190^{\circ} \mathrm{C}$ for $2 \mathrm{~h}$.
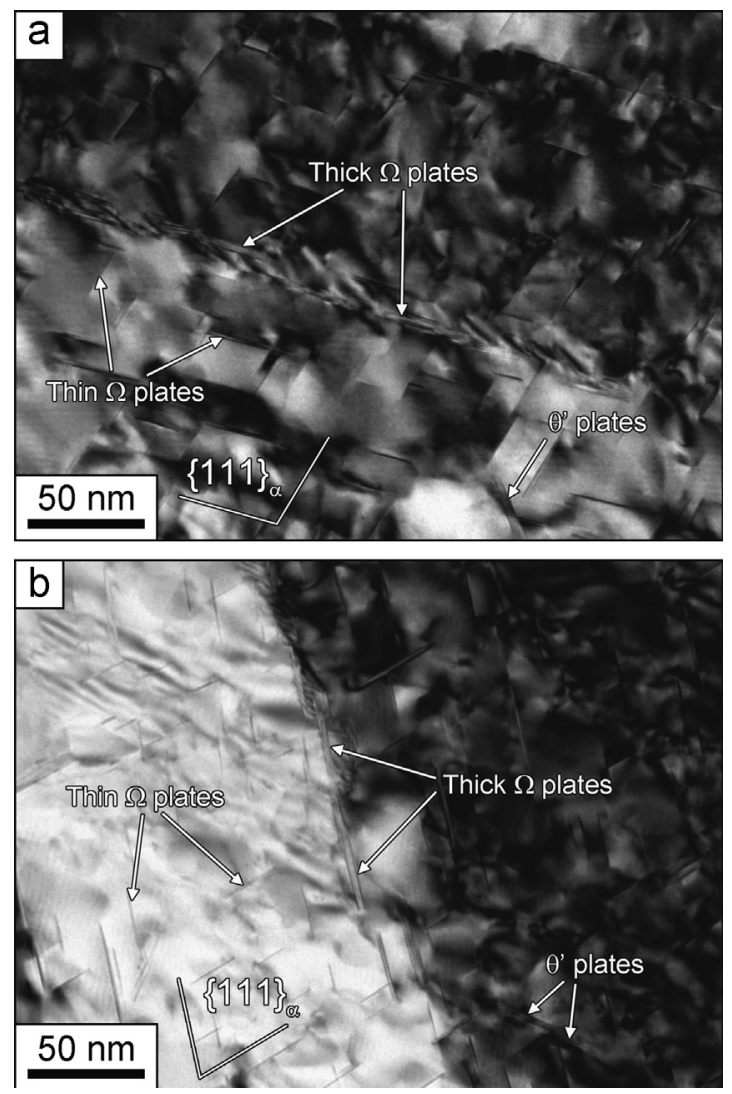

Fig. 12. Bright-field TEM images and SAED patterns taken along $\langle 110\rangle_{\alpha}$ directions for alloy cold rolled to $60 \%(\varepsilon \sim 0.92)$ (a) and $80 \%(\varepsilon \sim 1.61)$ (b).
UTS in the Al-Cu-Mg-Ag alloys due to the peak-aged conditioning after pre-straining by cold rolling with a reduction of $80 \%(\varepsilon \sim 1.61)$ despite the low aspect ratio of the $\Omega$-phase platelets. However, the appearance of a thick $\Omega$-phase with local semi-coherent edge faces may reduce the fracture toughness and creep resistance of the alloy [39]. These properties are critically important for the use of $\mathrm{Al}-\mathrm{Cu}-\mathrm{Mg}-\mathrm{Ag}$ alloys in the aviation industry. The optimal TMP is T840 temper, which allows for the retention of a dispersion of thin $\Omega$-phase plates and provides high strength that is only slightly less in the $\mathrm{L}$ direction than after the T880 temper.

\section{Conclusions}

1) Pre-strain by cold rolling is effective in increasing the strength of $\mathrm{Al}-\mathrm{Cu}-\mathrm{Mg}-\mathrm{Ag}$ alloys. In the T6 condition, the YS and UTS of the alloy are $478 \pm 4$ and $522 \pm 8 \mathrm{MPa}$, respectively, with $\delta \sim 8.0 \pm 1.3 \%$. In the T840 condition, this alloy exhibits YS and UTS of $527 \pm 6$ and $572 \pm 6 \mathrm{MPa}$, and the elongation-to-failure, $\delta$, is $6.3 \pm 0.7 \%$ in the longitudinal test direction. Under both of these conditions, the alloy contains dispersions of thin plates of the $\Omega$-phase within grain interiors and on grain boundaries, respectively. Further increases in the rolling reduction prior to aging lead to insignificant increases in the strength in the $\mathrm{T}$ direction, the appearance of anisotropy in the mechanical behavior and the precipitation of thick plates of the $\Omega$-phase on the deformation-induced grain boundaries.

2) Pre-strain prior to aging significantly changes the precipitation sequence, which can be written within grain interiors as follows:

$\mathrm{SSSS} \rightarrow \mathrm{GPB} 2 / \mathrm{S}^{\prime \prime}-$ phase $\rightarrow \Omega-$ phase 

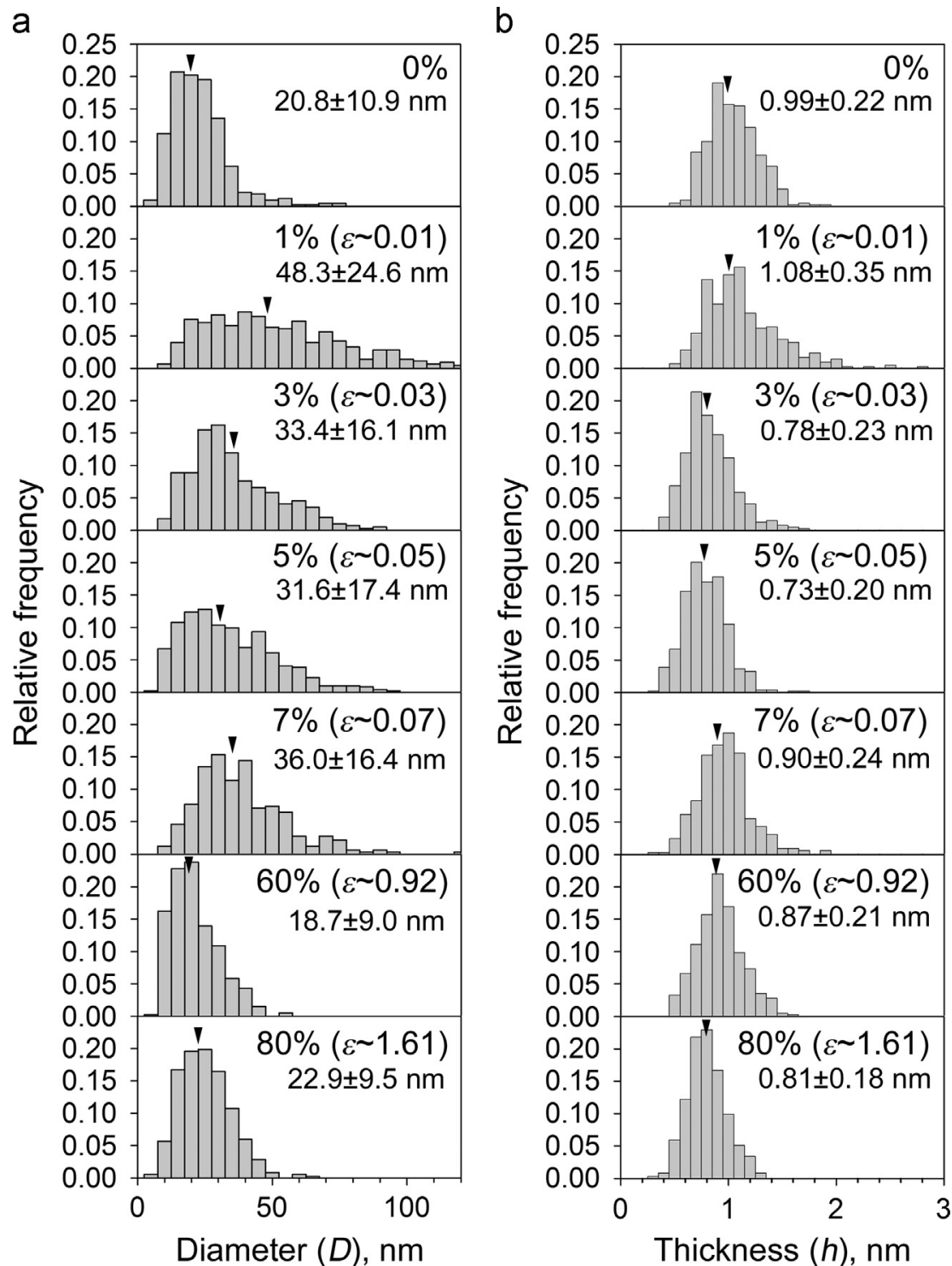

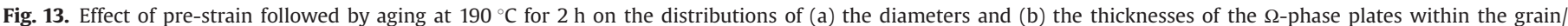
subgrain interiors.
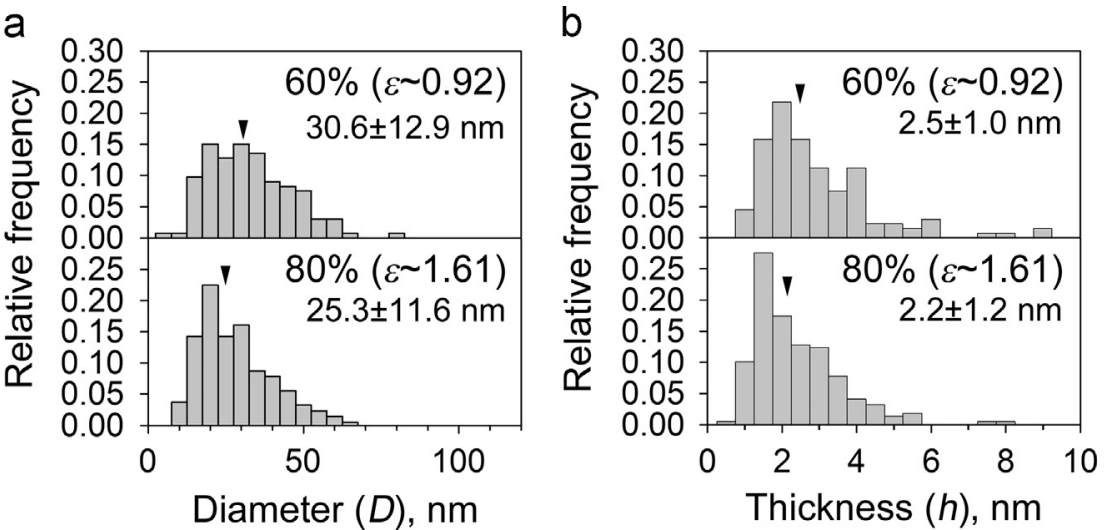

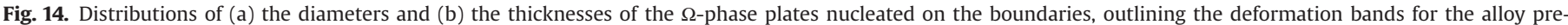
strained using rolling with a reduction of $60 \%(\varepsilon \sim 0.92)$ and $80 \%(\varepsilon \sim 1.61)$ followed by aging at $190{ }^{\circ} \mathrm{C}$ for $2 \mathrm{~h}$. 

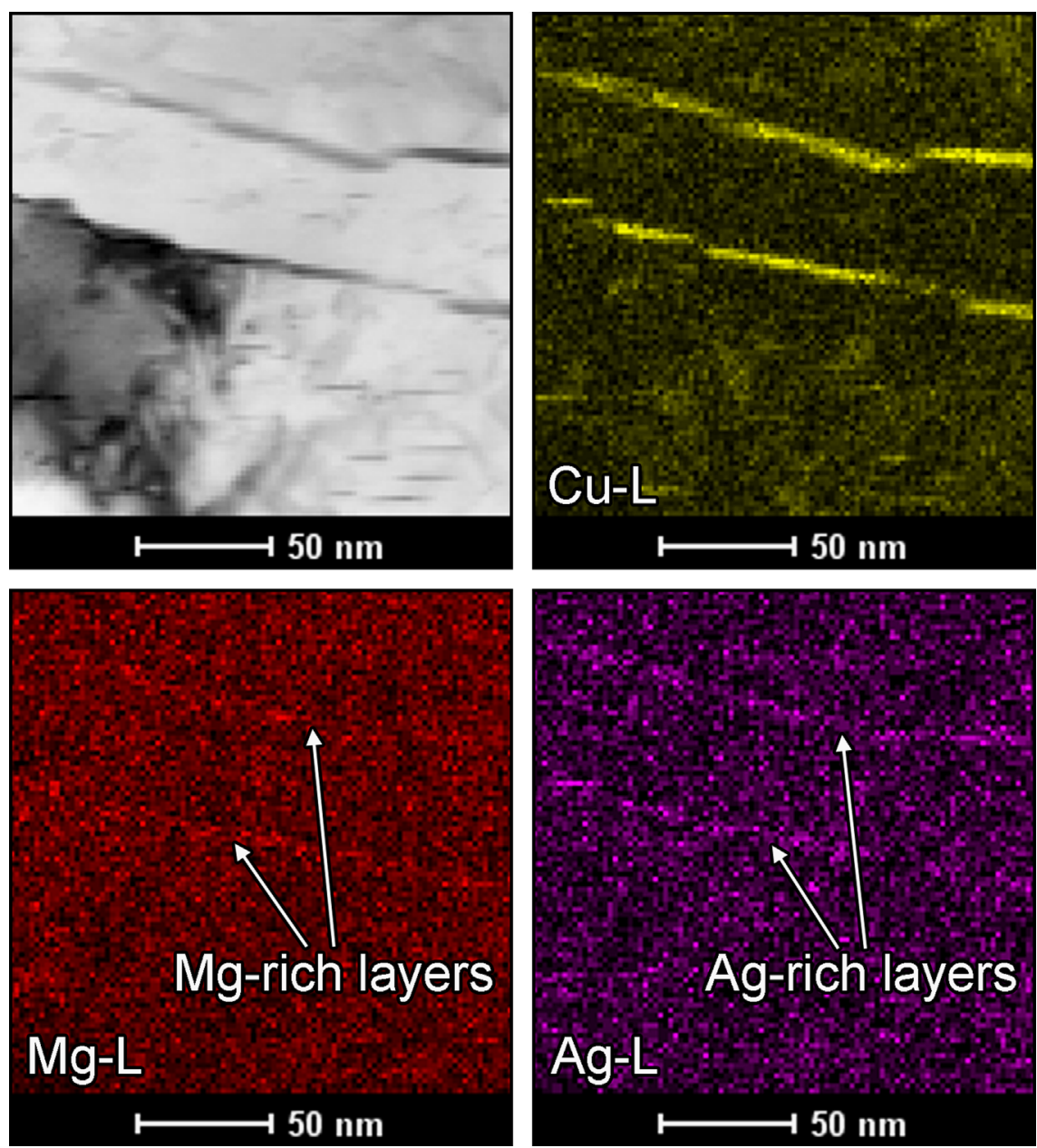

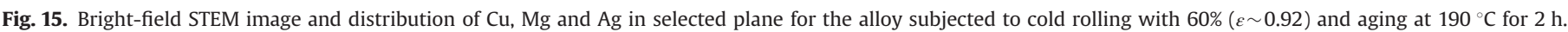
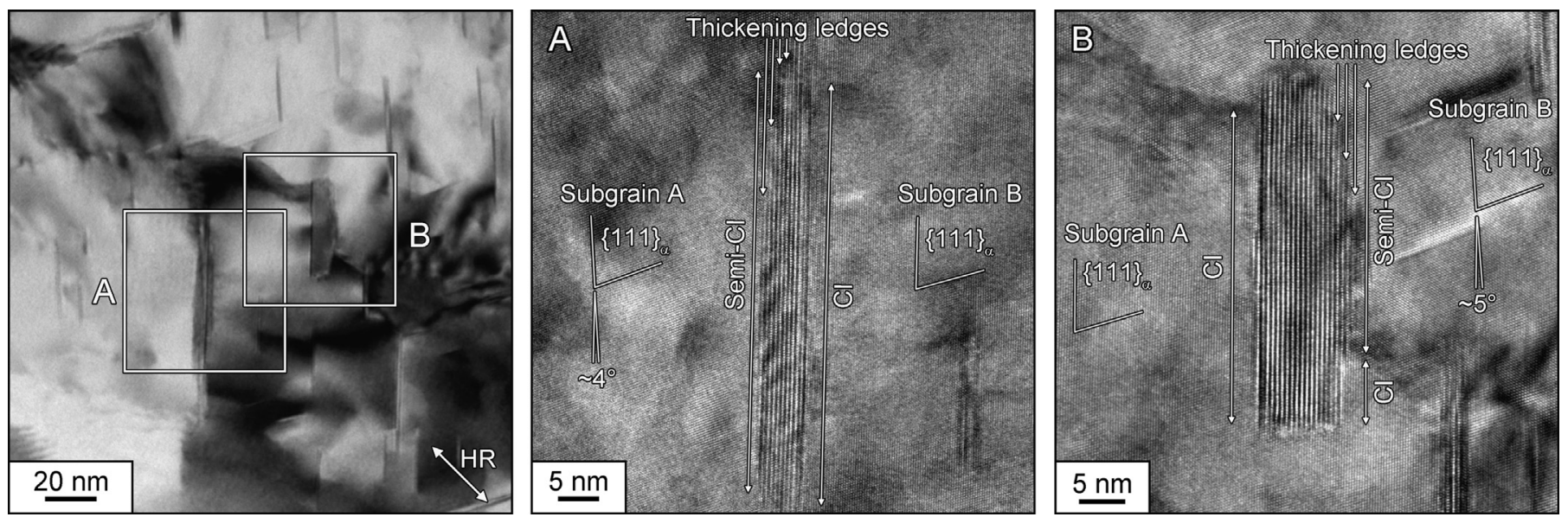

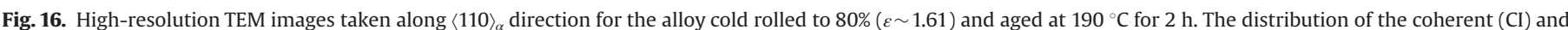
semi-coherent broad interfaces (Semi-CI) of thick $\Omega$ plates can be observed.

and on dislocations and deformation-induced boundaries as follows:

$$
\begin{aligned}
& \text { SSSS } \rightarrow \theta^{\prime}-\text { phase }+\mathrm{S} 1-\text { phase } \rightarrow \Omega-\text { phase }+\theta^{\prime}-\text { phase } \\
& \quad+\mathrm{S} 1-\text { phase }
\end{aligned}
$$

Pre-strain disrupts the clustering of $\mathrm{Ag}-\mathrm{Mg}$ with $\mathrm{Cu}$ atoms, which stops the formation of GP zone and facilitates the precipitation of the $\theta^{\prime}$-phase and the Type I $S^{\prime}$-phase at dislocations. The formation of well-defined deformation bands induces the boundary precipitations of thick $\Omega$-phase plates and dispersoids of S1-phase with size $\leq 5 \mathrm{~nm}$ and round shape. One half of broad interfaces of the $\Omega$-phase is fully coherent, while the other part has a fully or partially semi-coherent structure. 


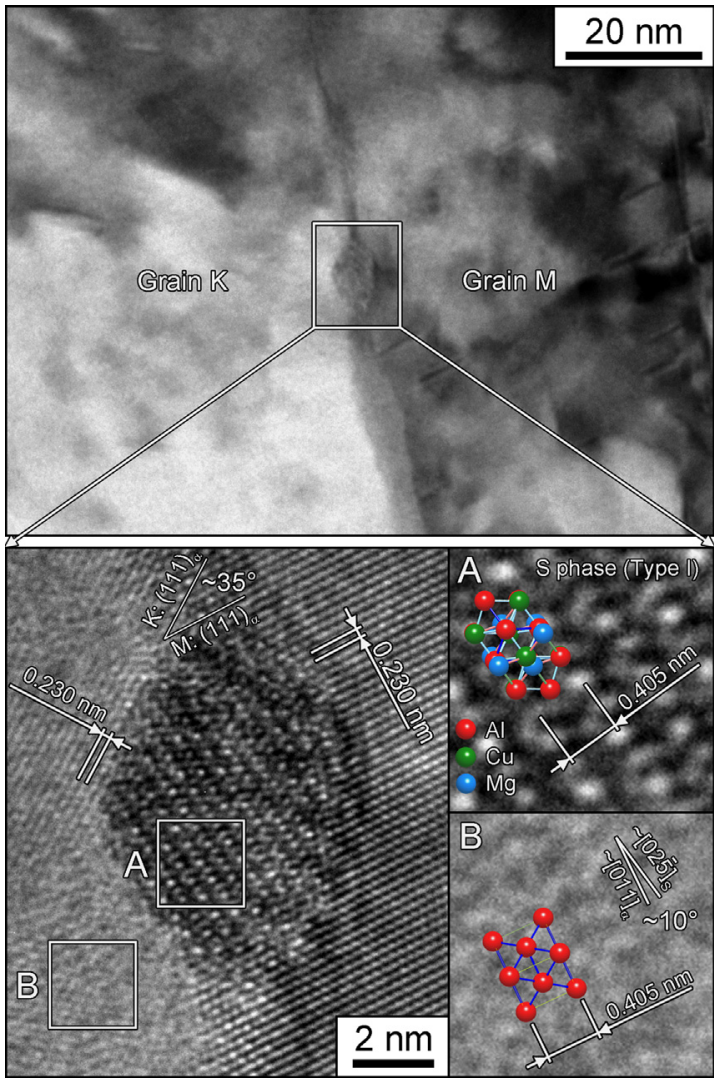

Fig. 17. Bright-field TEM and high-resolution TEM images of S-phase precipitate for the alloy subjected to cold rolling with $80 \%$ and aging at $190{ }^{\circ} \mathrm{C}$ for $2 \mathrm{~h}$. Zone axes of $\langle 110\rangle_{\alpha}$ and $\langle 073\rangle_{S}$.

\section{Acknowledgments}

The results of this work were produced in the joint project of USATU (Ufa State Aviation Technical University) and UMPO (Ufa Engine Industrial Association) with the title "Elaboration and industrial development of high-precision shaping coordinated technologies and superficial hardening of responsible details from Al-alloys with heightened constructional energy efficiency," implemented under the Contract no. 40/10-30976/NCh-NCh-01-13-KhG sponsored by the Ministry of Education and Science of the Russian Federation (Contract no. 02.G25.31.0010 between UMPO and the Ministry of Education and Science of the Russian Federation) through the Resolution of the Russian Federation Government No. 218 from April 9, 2010. The authors are grateful to the staff of the Joint Research Center, Belgorod State University for their assistance with the mechanical and structural characterizations.

\section{References}

[1] I.J. Polmear, G Pons, Y Barbaux, H. Octor, C Sanchez, A.J. Morton, W.E. Borbidge, S. Rogers, Mater. Sci. Technol. 15 (1999) 861-868.

[2] F.J. Nie, B.C. Muddle, J. Phase Equilib. 19 (1998) 543-551.

[3] F.J. Nie, B.C. Muddle, Scr. Mater. 42 (2000) 409-413.

[4] C.R. Hutchinson, X. Fan, S.J. Pennycook, G.J. Shiflet, Acta Mater. 49 (2001) 2827-2841.

[5] L. Sun, D.L. Irving, M.A. Zikry, D.W. Brenner, Acta Mater. 57 (2009) 3522-3528.

[6] S.P. Ringer, K. Hono, I.J. Polmear, T. Sakurai, Acta Mater. 44 (1996) 1883-1898.

[7] M. Gazizov, R. Kaibyshev, Mater. Sci. Eng. A 588 (2013) 65-75.

[8] L. Reich, M. Murayama, K. Hono, Acta Mater. 46 (1998) 6053-6062.

[9] M. Vural, J. Caro, Mater. Sci. Eng. A 520 (2009) 56-65.

[10] I.J. Polmear, Light Alloys. From Traditional Alloys to Nanocrystals, third ed., Butterworth-Heinemann/Elsevier, Oxford (UK), 2006.

[11] S. Bai, Z. Liu, X. Zhou, P. Xia, S. Zeng, J. Alloy. Compd. 602 (2014) 193-198.

[12] S.C. Wang, M.J. Starink, Int. Mater. Rev. 50 (2005) 193-215.

[13] S.P. Ringer, W. Yeung, B.C. Muddle, I.J. Polmear, Acta Metall. Mater. 42 (1994) 1715-1725.

[14] D. Bakavos, P.B. Prangnell, B. Besb, F. Eberl, Mater. Sci. Eng. A 491 (2008) 214-223.

[15] S.P. Ringer, B.C. Muddle, I.J. Polmear, Metall. Mater. Trans. 26A (1995) 1659-1671.

[16] Y.-T. Chen, Sh.-L. Lee, H.-Y. Bor, J.-Ch. Lin, Metall. Mater. Trans. 44A (2013) 2831-2838.

[17] D.A. Porter, K.E. Esterling, M. Sherif, Phase Transformation in Metals and Alloys, third ed., CRS Press Inc., London, 2009.

[18] N. Ünlü, B.M. Gable, G.J. Shiflet, E.A. Starke, Metall. Mater. Trans. 34A (2003) 2757-2769.

[19] J. da Costa Teixeira, D.G. Cram, L. Bourgeois, T.J. Bastow, Acta Mater. 56 (2008) 6109-6122.

[20] Y.-T. Chen, S.-L. Lee, H.-Y. Bor, J.-C. Lin, Metall. Mater. Trans. A 44 (2013) 2831-2838.

[21] A. Deschamps, B. Decreus, F. De Geuser, T. Dorin, M. Weyland, Acta Mater. 61 (2013) 4010-4021.

[22] Th. Dorin, A. Deschamps, F. De Geuser, Ch. Sigli, Acta Mater. 75 (2014) 134-146.

[23] Y. Huang, J.D. Robson, P.B. Prangnell, Acta Mater. 58 (2010) 1643-1657.

[24] M. Gazizov, V. Teleshov, V. Zakharov, R. Kaibyshev, J. Alloy. Compd. 509 (2011) 9497-9507.

[25] M. Gazizov, R. Kaibyshev, J. Alloy. Compd. 527 (2012) 163-175.

[26] D.B. Williams, C.B. Carter, Transmission Electron Microscopy, third ed., Springer, New York, 2009.

[27] J.F. Nie, B.C. Muddle, Acta Mater. 56 (2008) 3490-3501.

[28] R. Kaibyshev, K. Shipilova, F. Musin, Y. Motohashi, Mater. Sci. Eng. A 396 (2005) $341-351$.

[29] F.J. Humphreys, M. Hatherly, Recrystallization and Related Annealing Phenomena, second ed., Elsevier, Oxford, 2004.

[30] Y.L. Zhao, Z.Q. Yang, Z. Zhang, G.Y. Su, X.L. Ma, Acta Mater. 61 (2013) 1624-1638.

[31] M.J. Styles, C.R. Hutchinson, Y. Chen, A. Deschamps, T.J. Bastow, Acta Mater. 60 (2012) 6940-6951.

[32] L. Kovarik, P.I. Gouma, C. Kisielowski, S.A. Court, M.J. Mills, Acta Mater. 52 (2004) 2509-2520.

[33] A. Charai, T. Walther, C. Alfonso, A.-M. Zahra, C.Y. Zahra, Acta Mater. 48 (2000) 2751-2764.

34] S.C. Wang, M.J. Starink, Acta Mater. 55 (2007) 933-941.

[35] L. Kovarik, S.A. Court, H.L. Fraser, M.J. Mills, Acta Mater. 56 (2008) 4804-4815.

[36] N. Hansen, Scr. Mater. 51 (2004) 801-806.

[37] V. Kulitskiy, S. Malopheyev, R. Kaibyshev, Mater. Sci. Forum 794-796 (2014) 1187-1192.

[38] Z.J. Li, G. Winther, N. Hansen, Acta Mater. 54 (2006) 401-410.

[39] M. Gazizov, I. Zuiko, R. Kaibyshev, Mater. Sci. Forum 794-796 (2014) 278-283. 